\title{
Five-year follow-up study of patients with persistent vegetative state
}

\author{
K HIGASHI,* M HATANO, $\dagger$ S ABIKO, $\dagger \quad$ K IHARA, \\ S K A T A Y A M A,, Y W A K U T A,, T OKAMUR A , $\dagger$ \\ A N D T Y A M A S H I T A $\S$ \\ From the Department of Neurosurgery, Kitakyushu Central Hospital, Kitakyshu, ${ }^{*}$ the Department \\ of Neurosurgery, Yamaguchi University School of Medicine, Ube, $\dagger$ the Department of Neurosurgery, \\ Tokuyama Central Hospital, Tokuyama, $\ddagger$ and the Department of Neurosurgery, Kokura Memorial \\ Hospital, Kitakyushu,§ Japan
}

SUMMARY One hundred and ten patients with persistent vegetative state, were followed up for a period of five years from 1973 to 1978. Seventy-three per cent of the patients died during the period while about $10 \%$ of them recovered partially from the vegetative state. Among the recovered patients, only three became able to communicate, but two of these are not independent for their daily activities. Reactivity and clinical symptoms of 30 survivors were examined, but no great changes occurred during the last two years of the study.

We previously reported the results of epidemiological studies on 110 patients with a persistent vegetative state in 1977.1 We have continued to observe the same group of patients and we summarise here further follow-up data at five years.

\section{Materials and methods}

Criteria for selection of the patients and method of survey have been described in the previous paper. We continued to keep contact with attending physicians in each hospital as to outcome of the patients once a year, and we examined surviving patients at the end of the five-year follow-up period (May 1978).

\section{Fate of the patients}

Eighty patients had died by 31 May 1978; the overall mortality rate for five years was $72 \cdot 7 \%$. Survival rates for every six months are shown in the figure. Mortality for three and five years, with reference to causative diseases, are shown in the

Address for reprint requests: Dr Kenichiro Higashi, Department of Neurosurgery, Kitakyushu Central Hospital 1-4-5 Shiragane, Kokurakita-ku, Kitakyushu, 802 Japan. table. The mortality was high in the groups with cerebrovascular lesion and brain tumours, while it was relatively low in those with intoxication and head injury at both three and five years. No patients died during the last two years in the groups with developmental disorders, cerebral anoxia, brain tumours, and intoxication.

We reported in the previous paper that eight patients had been assessed as no longer vegetative at the end of the three-year follow-up study. Among them, three had begun to comprehend

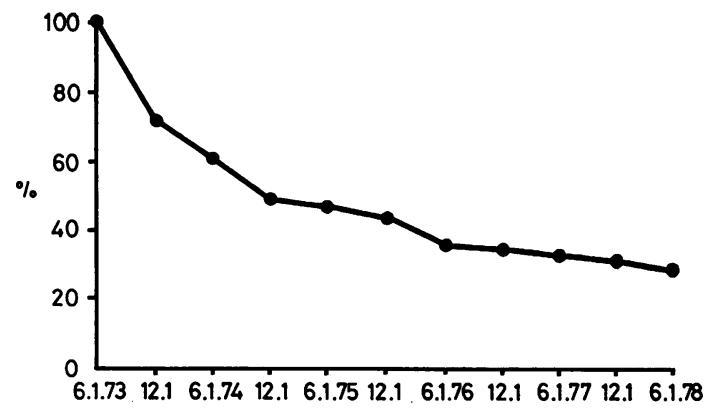

Figure Survival rates of vegetative patients at intervals of six months. 
Table Mortality rate related to the cause of brain damage

\begin{tabular}{|c|c|c|c|c|}
\hline Cause of brain damage & $\begin{array}{l}\text { No of cases at } \\
\text { initial survey }\end{array}$ & $\begin{array}{l}\text { Average age at } \\
\text { initial survey }\end{array}$ & $\begin{array}{l}\text { Mortality rate for } \\
3 \text { years }(\%)\end{array}$ & $\begin{array}{l}\text { Mortality rate for } \\
5 \text { years }(\%)\end{array}$ \\
\hline $\begin{array}{l}\text { Head injury } \\
\text { Cerebrovascular lesion } \\
\text { Developmental disorder } \\
\text { Cerebral anoxia } \\
\text { Brain tumour } \\
\text { Inflammation } \\
\text { Regressive-degenerative disease } \\
\text { Intoxication } \\
\text { Total }\end{array}$ & $\begin{array}{r}38 \\
21 \\
14 \\
12 \\
10 \\
7 \\
4 \\
4 \\
110\end{array}$ & $\begin{array}{l}41 \cdot 7 \\
63 \cdot 0 \\
11 \cdot 8 \\
19 \cdot 2 \\
40 \cdot 8 \\
38 \cdot 3 \\
53 \cdot 8 \\
44 \cdot 5 \\
39 \cdot 7\end{array}$ & $\begin{array}{l}55 \cdot 3 \\
76 \cdot 2 \\
71 \cdot 4 \\
66 \cdot 7 \\
80 \cdot 0 \\
57 \cdot 1 \\
50 \cdot 0 \\
50 \cdot 0 \\
64 \cdot 5\end{array}$ & $\begin{array}{l}65 \cdot 8 \\
90 \cdot 5 \\
71 \cdot 4 \\
66 \cdot 7 \\
80 \cdot 0 \\
71 \cdot 4 \\
75 \cdot 0 \\
50 \cdot 0 \\
72 \cdot 7\end{array}$ \\
\hline
\end{tabular}

and communicate, while the remaining five patients had recovered only to the state that they obeyed simple commands, spoke monosyllabic words or both. Of these "recovered" cases, two died and one became vegetative again thereafter. No new recovered cases were added during the period of these two years. Therefore, five patients out of 30 survivors were estimated to be "recovered" at the examination for the five-year follow-up study. Of these five cases only two regained the ability to communicate and move around by themselves, while the remaining three patients only responded to calling or to simple commands, and were confined to their beds. One of the two communicating survivors is a 61-yearold female who had become vegetative following a subarachnoid haemorrhage seven years previously. She remained in a vegetative state for three years and then gradually recovered responsiveness. During the last four years, she was alert and well oriented. The other patient is a 26-year-old male who had become vegetative following cerebral anoxia 5.5 years previously. Eight months after the ictus he began to regain responsiveness and eventually recovered from the vegetative state. At the present time, both of these patients can read a newspaper, watch television and write their names skilfully. They can tell time from a watch and can calculate addition and subtraction with numbers of two figures. They respond to questions promptly and correctly, and can speak well. They can eat by themselves. Although they are unable to stand and walk because of contracture of their knee and ankle joints, they can move around by wheelchair if they are assisted to sit in it.

Besides the eight recovered cases mentioned above, four other patients had recovered during the first three years. However, two of them had become vegetative again and two had died before the three-year follow-up study. Therefore, a total of twelve patients regained some responsiveness temporarily or permanently. Four of these twelve patients died, so that the mortality rate for recovered patients was $33.3 \%$, which is less than the overall mortality rate.

\section{Clinical features}

We examined 30 patients who survived after five years from the initial survey. The results of the examination were then compared with the data obtained at the three-year follow-up study. Results show that reactivity and neurological findings of these patients have not changed greatly during the recent two years. Minor changes were observed in some symptoms or signs at the final examination; an increased number of the patients having quadriplegia were more responsive to certain stimuli such as pain or noise, and some reflexes such as spinociliary and abdominal were more readily elicited.

\section{Discussion}

In spite of the common knowledge that the prognosis of patients in persistent vegetative states is extremely poor, there has so far been no precise study of the natural history of patients in this state. The present investigation confirmed our impression concerning the poor prognosis of vegetative patients: nearly $75 \%$ of the patients died during a five-year follow-up period despite attentive medical care.

Analysis revealed that the causative disease might influence mortality; in the group of cerebrovascular lesion patients, we found the highest mortality rate. This is partly explained by the fact that the stroke group consisted of older patients. Although the majority of the patients died from pulmonary infection, aged patients might have less resistance against infection. The group with brain tumours also showed high mortality, presumably owing to the progression of the primary disease. On the other hand, about 
$10 \%$ of the patients regained awareness temporarily or permanently during the five-year follow-up period. However, in the majority of these patients recovery was limited to a state in which they merely responded to calling or obeyed simple commands. Only two patients regained the ability to comprehend and to express their intentions. These patients are also able to move if assisted, but they are unable to care for themselves; in other words, they are almost hopeless in terms of social adaptability.

Clinical symptoms of most patients living after five years were essentially unchanged in com- parison with the three-year follow-up study. In general, patients who survived a longer period showed stable clinical manifestations characteristic of a vegetative state, the result of devastating cortical and subcortical damage, in spite of well maintained brain stem functions.

\section{Reference}

1 Higashi K, Sakata Y, Hatano M, et al. Epidemiological studies on patients with persistent vegetative state. J Neurol, Neurosurg Psychiatry 1977; 40:876-85. 